\title{
Adivinha quem é sobre a tabela periódica: o jogo como recurso didático no ensino de química no $9^{\circ}$ ano do Ensino Fundamental
}

Guess who is the periodic table: the games as a didatic resource in the teaching of chemistry in the 9th grade of elementary school

Resumo: No ensino de Ciências no $9^{\circ}$ ano do ensino fundamental (EF), ao lecionar os conteúdos de química percebe-se que os alunos apresentam grande dificuldade no que tange a aprendizagem sobre a tabela periódica. Nesse sentido, nota-se a necessidade da utilização de estratégias de explanaçãodiferenciadas que motivem o aluno e potencialize o processo de ensino e aprendizagem. Dessa forma, o jogo pode ser um importante recurso didático, pois pode promove a interação e comunicação entre os alunos e estimular o raciocínio lógico. Este trabalho apresenta um jogo intitulado "Adivinha quem é sobre a tabela periódica", como um recurso didático visando contribuir significativamente no processo de ensino e aprendizagem sobre os temas tabela periódica e elementos químicos. Com isso, o trabalho foi realizado em uma turma de $9^{\circ}$ ano do EF de uma escola da rede estadual de São Mateus-ES Os resultados alcançados caracterizam a pesquisa como qualitativa e mostram a importância da utilização de recursos que facilitam o processo de ensino e formação dos alunos e aproximação do conteúdo estudado com o cotidiano.

Palavras-Chave: Tabela Periódica.ensino de química.jogos

Abstract: In science teaching in the 9th grade of elementary school (PE), when teaching the chemistry content, it is noticed that students have great difficulty in terms of learning about the periodic table. In this sense, there is a need to use differentiated explanation strategies that motivate the student and enhance the teaching and learning process. Thus, the game can be an important educational resource, as it can promote interaction and communication between students and stimulate logical reasoning. This work presents a game entitled "Guess who's on the periodic table", as a didactic resource aiming to contribute significantly to the teaching and learning process on the themes of periodic table and chemical elements. As a result, the work was carried out in a 9th grade PE class at a state school in São Mateus-ES. The results achieved characterize the research as qualitative and show the importance of using resources that facilitate the teaching and training process of students and approximation of the content studied with everyday life.

Keywords: Periodic Table.chemical.chemistry.games

\section{Introdução}

Atualmente, notamos que 0 ensino de ciências no $9^{\circ}$ no Ensino Fundamental (EF), é permeado por desafios tanto para professores quanto para os alunos, já que consiste no ensino de conteúdos referente às disciplinas 
de química e física. No que se diz respeito aos professores, a maior dificuldade que vivenciamos é em relação aos conteúdos, visto que os mesmos não se sentem seguros em ministrar sobre alguns temas já que sua formação inicial não contempla os conteúdos necessários para o ensino de química e física no $9^{\circ}$ do EF. É necessário que o professor dessa etapa de ensino conheça o suficiente dos conteúdos de química e física necessários para ministrar a aula e responder possíveis questionamentos feitos em sala de aula (LIMA E MAUÉS, 2006).

No que tange aos alunos, a maior dificuldade se dá devido a utilização de cálculos matemáticos e à abstração dos conteúdos, visto que pouco dialogam com a realidade. Maior parte dos alunos relata que as aulas de ciência, principalmente no ensino de química, são permeadas por nomes estranhos, símbolos e fórmulas, como relatam Roque e Silva (2008, p. 1) que "a linguagem da química descreve através de modelos, representados por fórmulas estruturais, equações, gráficos e figuras, as coisas do mundo como compreendida pelo químico", ou seja, é uma linguagem específica para descrever os fenômenos. A falta da interação entre as aulas e o cotidiano dos alunos contribui para que o aluno não compreenda o assunto, já que não contempla sua realidade. As metodologias aplicadas no ensino de ciências, no que se refere aos conteúdos de química, pode promover a "decoreba" dos conceitos trabalhados, por exemplo, através da confecção de atividades e questionários (COSTA, 2010).

O baixo interesse por parte dos alunos nessa etapa escolar está relacionado a diversos fatores. A falta de domínio dos conteúdos de física e química por parte de alguns professores, visto que a formação inicial dos professores de ciências está distante da realidade vivenciada em sala de aula (ROSA, 2015). Outro agravante é a falta da utilização de metodologias e recursos didáticos necessários para facilitar o processo de aprendizagem dos alunos, pode estar diretamente relacionado a esse baixo desempenho. $O$ desenvolvimento dos conteúdos de química e física de forma mais lúdica através de jogos e realização de experimentos, por exemplo, proporciona ao aluno estimula o pensamento crítico e facilita a compreensão dos conteúdos 
abordados e pode despertar no aluno o interesse pela matéria, dessa forma é possível que inicie o ensino médio com uma visão menos abstrata de tais disciplinas (BRAULIO e ALMEIDA, 2013).

A utilização do jogo com um recurso didático pode auxiliar no processo cognitivo, social, e estimula a criatividade dos alunos. Dessa forma, o professor precisar utilizar os diversos recursos pedagógicos disponíveis com o objetivo de contribuir no processo de aprendizagem e compreensão dos conceitos pelos alunos (ROCHA e RODRIGUES, 2018).

Quando se fala que o jogo tem um cunho educacional, ele não deve ser desenvolvido sem um conhecimento prévio, dessa forma é necessário que o professor tenha clareza dos seus objetivos e apresente um embasamento teórico e metodológico. Para um jogo ser considerado um recurso pedagógico, é necessário que seja contextualizado e que os materiais utilizados sejam concretos e relacionados com o contexto histórico, sendo indispensável que o professor conheça a funcionalidade do jogo e identifique as necessidades dos alunos, realizando as adaptações adequadas (RAU, 2007).

Dessa maneira, para que um ensino de Ciências seja significativo é fundamental diversificar as metodologias, estratégias e recursos didáticos utilizados nas aulas. Práticas de ensino diferenciadas contribuem no processo ensino-aprendizagem, sensibilização e motivação dos alunos, fazendo com que os mesmos estabeleçam uma relação entre os conceitos vistos em sala de aula com o seu cotidiano; essa dificuldade pode ser minimizada através da utilização de aulas experimentais, práticas e lúdicas (KRASILCHIK, 2008).

É necessária a participação dos alunos para o desenvolvimento dessas estratégias de ensino, que é evidenciada através da exposição do conhecimento prévio, interesse e motivação dos alunos pelo conteúdo estudado. Vale ressaltar que para o envolvimento do aluno como parte ativa, é necessário que os mesmos apresentem noções de conhecimentos específicos que só serão adquiridos através de um ensino que contemple os problemas em uma visão ampla e contextualizada (BRASIL, 1996). Esses aspectos devem ser considerados em todas as etapas de aprendizagem, umas das práticas de ensino que pode ser utilizada para contextualizar o ensino é o jogo. 
O jogo é um recurso bem visto pelos alunos, pois promove a interação, estimula a comunicação, o raciocínio crítico e lógico dos alunos, tornando-se um importante agente para a construção do processo ensino-aprendizagem (CASTRO; FRASSON-COSTA, 2011). O jogo é um objeto sociocultural, além de ser uma atividade natural utilizada no desenvolvimento dos processos psicológicos básicos dos indivíduos. Batllori (2003) afirma que o jogo contribui no desenvolvimento da imaginação ajudando na exploração das limitações, contribuindo para a resolução de problemas.

O ensino acerca da tabela periódica (TP) é de extrema importância e tem caráter introdutório no ensino de química, aplicando os conceitos básicos e os símbolos, dessa forma o ensino precisa motivar o aluno para levá-lo a uma aprendizagem significativa. Por ser um conteúdo introdutório, caso o aluno não aprenda de forma significativa, todo o ensino de química será prejudicado, haja vista que os conceitos básicos trabalhados não foram compreendidos pelos alunos. Observa-se que os alunos do ensino fundamental não se interessam pela disciplina de química, porque não conseguem relacionar o conteúdo aprendido com seu cotidiano, com isso traz a dificuldade na compreensão e o seu desinteresse pela matéria (CASTRO; FRASSON-COSTA, 2011).

A TP é um importante instrumento didático e de pesquisa utilizado no ensino de química e áreas afins, dessa forma é necessário que os alunos conheçam os elementos que a compõem (MORSCHHEISER et al., 2017). Por muito tempo os alunos eram obrigados a decorar todos os nomes e símbolos químicos da TP, tornando o processo ensino-aprendizagem mecânico. Para Santos e Araújo (2017), a utilização de jogos didáticos sobre a TP é tratada como um parâmetro de compreensão dos elementos químicos, sendo a simbologia, a localização de cada elementos (família ou período) e sua utilização cotidiana.

O ensino de ciências no $9^{\circ}$ do EF traz em seu currículo os conteúdos de química e física, a fim de introduzir alguns conceitos que serão utilizados ao longo do ensino médio. É possível notar uma grande dificuldade no processo ensino e de aprendizagem devido a disciplina de ciências, no qual os docentes sentem inseguros em ministrar os conteúdos de química e física, por acharem 
complexos (GOMES; OLIVEIRA, 2007). Desse modo, podemos notar a grande falta de interesse dos alunos por tais disciplinas, no qual muitos consideram "difícil", o que leva os alunos a apenas decorar alguns conceitos, gerando conhecimentos abstratos e sem significados (UNTAR, 2008)

A falta da interação entre as aulas e o cotidiano dos alunos contribui para que o aluno não compreenda o assunto, já que não contempla sua realidade. Sabemos que é no Ensino Fundamental ( $9^{\circ}$ ano), que provavelmente o aluno terá o primeiro contato com a tabela, e esta é sem dúvida um instrumento importante no ensino da química (COSTA, 2010). Dessa forma, trabalhá-la de maneira lúdica e interativa o ensino torna-se mais divertido e enriquecedor já que aborda os conceitos explorados, é uma ferramenta metodológica estimulante e dinâmica e proporciona a participação dos alunos no decorrer de toda a atividade. A partir das dificuldades encontradas na compreensão dos elementos químicos da tabela periódica, o presente trabalho apresenta uma possível estratégia que visa contribuir significativamente no processo de ensino e aprendizagem destes conteúdos.

Dessa forma podemos recorrer ao lúdico, buscando a promoção de um ensino contextualizado e que tenha significado para o aluno. $O$ ensino se torna mais eficaz quando há uma relação entre a prática e a teoria. Baseado nas premissas da Teoria da Aprendizagem Significativa de Ausubel, podemos discutir o ensino através do lúdico, que surge como uma oportunidade de facilitador do ensino (MOREIRA 2012). Uma aprendizagem significativa é a ampliação de ideias e informações que o aluno já apresenta, associado e levando em consideração o contexto na qual o aluno está inserido e o objeto de estudo, dessa forma é possível relacionar as informações já existentes com o conhecimento que será integrado através dos estudos.

Mesmo a tabela periódica sendo deixada de lado por alguns profissionais, ainda assim é um material muito utilizado no $9^{\circ}$ ano do ensino fundamental, não para memorização, mas para conhecimento e aproximação dos elementos químicos com o cotidiano do aluno. Dessa forma, este trabalho mostra que a tabela periódica pode ser estudada de forma diferenciada, 
buscando utilizar ferramentas pedagógicas, como o jogo, para promover 0 aprendizado.

\section{Metodologia}

Nesta pesquisa foi adotada a abordagem qualitativa considerando as experiências cotidianas e conhecimento prévio, promovendo a construção de conhecimento. Dessa forma é necessário a aproximação entre os sujeitos do processo ensino-aprendizagem permitindo a compreensão para reconhecimento dos significados tendo como abordagem inicial $O$ conhecimento prévio dos alunos (ANDRÉ, 2013). A pesquisa foi desenvolvida em uma turma, com 32 alunos, do $9^{\circ}$ ano do Ensino Fundamental de uma escola estadual de São Mateus-ES.

A metodologia de ensino desenvolvida no presente trabalho baseou-se nos três momentos pedagógicos descritos por Delizoicov e Angotti (1991), sendo a problematização inicial, organização do conhecimento e a aplicação do conhecimento. No presente trabalho, a problematização inicial é dada pela primeira interação entre o professor, os alunos e o assunto que foi abordado. Nessa etapa, os alunos compartilham os conhecimentos prévios e expõem situações do cotidiano vivenciadas por eles. Alguns questionamentos foram feitos nesse momento, como:

Vocês conhecem a tabela periódica?

O que vocês entendem por elementos químicos?

Os elementos químicos observados na tabela periódica fazem parte do nosso cotidiano?

A partir dessas discussões iniciais foi possível iniciar o segundo momento, a organização do conhecimento, na qual os alunos foram orientados sobre os conceitos científicos necessários para a compreensão da tabela periódica e os elementos químicos, através de aulas expositivas dialogadas e na confecção de atividades sobre o assunto. $O$ segundo momento foi desenvolvido em 5 aulas de 55 minutos cada, na qual as 4 primeiras aulas foi destinada para o desenvolvimento do conteúdo, e 1 aula para confecção de atividades e esclarecimento de dúvidas. 
No terceiro momento, denominado aplicação do conhecimento, os conceitos incorporados nos dois primeiros momentos são utilizados para compreensão através das situações resultantes do ensino. Nesse aspecto, inúmeras metodologias podem ser desenvolvidas para concretização do último momento, por exemplo, atividades de fixação, jogos e atividades experimentais. Nesse momento, foi proposto o jogo didático intitulado "Advinha quem é sobre a tabela periódica". O jogo foi aplicado em uma turma de $9^{\circ}$ ano do EF de uma escola da rede estadual de São Mateus-ES e teve por objetivo simplificar o ensino química no que tange o estudo sobre a tabela periódica, atuando como facilitador no processo de ensino-aprendizagem.

O jogo didático foi baseado nos conhecimentos prévios dos alunos e nas trocas de experiências em sala de aula, sendo assim a maioria dos elementos abordados já era conhecido por eles. Vale ressaltar que a atividade foi utilizada como uma revisão para a avaliação, visando uma melhor compreensão dos elementos químicos, assim como os símbolos, período e família de cada elemento. A atividade realizada foi uma adaptação de um jogo on-line (Figura 1) disponível no site do Professor Mazzei (Disponível em: https://professormazzei.com/mazzei-com/jogos-de-quimica/), que é um site gratuito que tem por objetivo ajudar alunos a compreender a química de uma forma mais leve e prazerosa.

Figura 1. Tela inicial do jogo on-line.

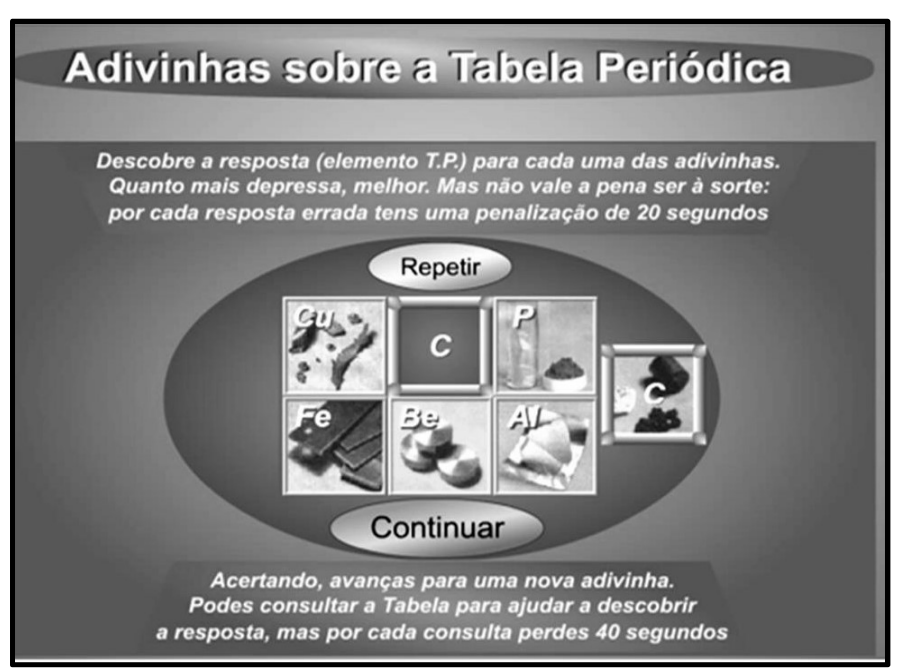

Fonte: Jogos de Química, Professor Mazzei. 
No site citado anteriormente, a recomendação da atividade é para alunos de ensino médio, porém pode ser adaptado para alunos de ensino fundamental e graduação. $O$ jogo on-line apresenta 64 perguntas. A atividade adaptada é composta por um banner com a tabela periódica, um painel confeccionado com isopor e envelopes de cartas. O objetivo do jogo era descobrir a resposta certa para cada advinha. Foram selecionados 18 elementos da tabela periódica (Quadro 1), no qual foi montado um painel com envelopes de carta. Na frente de cada envelope tinha o símbolo do elemento, e dentro dele um cartãozinho com as pistas.

Para a confecção do painel com os elementos químicos, foi utilizado uma placa de isopor de $20 \mathrm{~mm}$ de espessura $(50 \times 100 \mathrm{~cm})$, revestida com TNT preto. Foram utilizados 18 envelopes de carta $(16 \times 22 \mathrm{~cm})$ com cores diferentes, sendo 3 envelopes de cada cor, sendo: vermelho, amarelo, verde, roxo, branco, azul. Na parte externa do envelope foi escrito os símbolos dos elementos escolhidos (Quadro 1), já na parte interna de cada envelope foi colocado pista referentes aos elementos químicos.

Os envelopes foram fixados no painel utilizando alfinetes de mapas. A sala foi disposta em 4 grupos, contendo 8 alunos em cada grupo, em seguida foi realizado um sorteio para saber qual grupo iniciaria o jogo escolhendo o primeiro envelope. Após a escolha do envelope (Figura 2), realizou-se a leitura das pistas e os alunos deveriam acertar qual era o elemento.A cada pergunta advinha fornecido, o grupo tinha 2 minutos para responder a questão, caso 0 grupo não conseguisse responder, a vez passava para o grupo adversário.

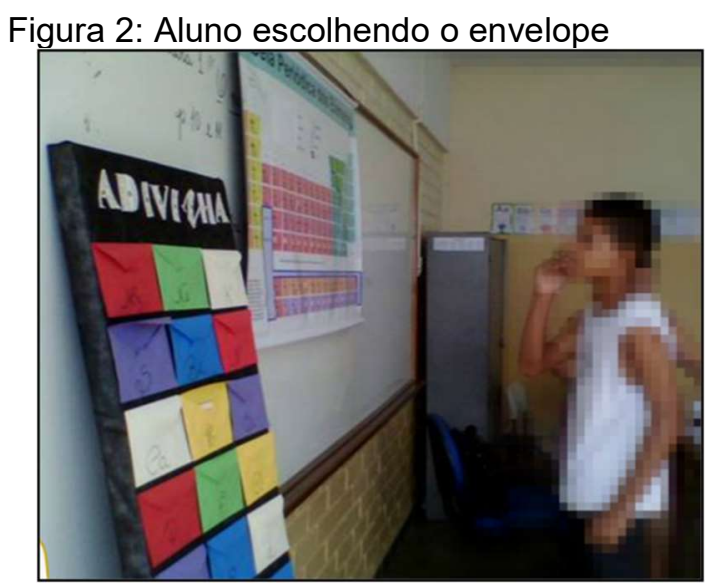

Fonte: Autor, 2019 
Quando eles acertaram, por exemplo, o envelope aberto era o do Boro, mas a respostas correta era o Flúor, então a resposta era colocada dentro do envelope do Flúor e era retirado as pistas que está dentro dele para ler para o próximo grupo e assim sucessivamente. Durante o jogo os alunos precisavam estar atentos as informações fornecidas pelo mediador e agilidade para consultar a tabela periódica. A ludicidade dessa atividade foi avaliada através da observação do envolvimento e a motivação dos alunos durante o jogo, nesse tipo de atividade percebeu grande euforia e a vontade de vencer. Quando os alunos apresentavam dúvidas referente as dicas, era informado a localização do elemento facilitando a compreensão.

Vale ressaltar que ao final do jogo não se aplicou nenhum questionário, visto que o objetivo era revisar os conteúdos para a avaliação. Dessa forma, a identificação do conhecimento prévio dos alunos é de grande importância nos processos de aprendizagem, pois facilita a explicação das regras do jogo bem como a leitura do painel ilustrativo elaborado para consulta (ZANON; OLIVEIRA, 2008).

\section{Resultados e discussões}

No início do jogo, foi notado que os alunos apresentavam um tipo de bloqueio quando se tratava da compreensão sobre a tabela periódica, já que é considerado um conteúdo difícil por eles nessa etapa de ensino. Quando se fala em jogo, os alunos, a princípio, apresentam receio por não saber como será o andamento do jogo e o grau de dificuldade do mesmo.

Conforme o jogo era desenvolvido, os alunos perceberam que a atividade tinha um caráter lúdico, assim o conteúdo tão temido por eles seria abordado de uma forma mais leve. A atividade aplicada proporciona um ambiente de aprendizado que permitia assim o envolvimento de todos os alunos. O jogo é uma ferramenta que pode auxiliar o processo de aprendizagem e estimula o interesse do aluno em relação ao conteúdo proposto, desenvolvendo diferentes experiências e colaborando na construção de novas descobertas (ZANON; OLIVEIRA, 2008).Para que um jogo se torne agente facilitador de ensino é necessário que ele seja bem elaborado, lúdico e 
atrativo, na qual desperte o interesse dos alunos, além de ser de fácil entendimento (SILVA; BIANCO, 2020).

Dentre os elementos escolhidos (Quadro1) para a prática havia elementos bastante conhecidos como o Nitrogênio $(\mathrm{N})$, por exemplo, e alguns não tão estudados como o Neônio (Ne). Dessa forma, nota-se a necessidade de estudar a importância e a aplicação/utilização dos elementos químicos no cotidiano, para que o conteúdo tenha significado para os alunos. É necessário quebrar os paradigmas do ensino de química quando se trata da tabela periódica, uma forma de realizar essa ação é aproximar os conteúdos a realidade do aluno.

Para tornar o ensino contextualizado é necessária uma aproximação da realidade vivenciada pelos alunos além de priorizar o conhecimento prévio dos mesmos, estabelecendo uma rede de relações entre situações significativas que servirá posteriormente de orientação para discussões resultantes do processo ensino-aprendizagem. O aluno aprenderá a partir do que ele já tem conhecimento, nesse sentido o conhecimento prévio dos alunos organizados de forma hierárquica influenciará a aprendizagem significativa dos novos conhecimentos adquiridos (PIRES et al 2020; MOREIRA, 2012).Dessa forma, uma aprendizagem contextualizada transforma o aluno um sujeito ativo no processo ensino-aprendizagem, além de proporcionar uma aprendizagem significativa (FREIRE, 1996).

Quando os alunos olharam o painel (Quadro 1) e perceberam que alguns símbolos ainda desconhecidos por eles, notou-se certo desconforto, porém a medida que as pistas sobre os elementos eram ditas, os alunos se envolveram no desafio de encontrar e saber sobre esses novos elementos.

Quadro 1. Elementos químicos escolhidos para a atividade.

\begin{tabular}{|c|c|c|}
\hline \multicolumn{3}{|c|}{ ELEMENTOS DA TABELA PERIÓDICA } \\
\hline Alumínio (Al) & Cálcio (Ca) & Hidrogênio (H) \\
\hline Argônio (Ar) & Cloro (Cl) & Lítio (L), \\
\hline Nitrogênio (N) & Enxofre (S) & Magnésio (Mg) \\
\hline
\end{tabular}




\begin{tabular}{|c|c|c|}
\hline Berílio $(\mathrm{Be})$ & Flúor $(\mathrm{F})$ & Neônio $(\mathrm{Ne})$, \\
\hline Boro $(\mathrm{B})$ & Fósforo $(\mathrm{P})$ & Oxigênio $(\mathrm{O})$, \\
\hline Potássio $(\mathrm{K})$ & Hélio $(\mathrm{He})$ & Silício $(\mathrm{Si})$ \\
\hline
\end{tabular}

As pistas (Tabela 1) sobre os elementos químicos utilizadas para a atividade eram de fácil compreensão, as informações contidas nos envelopes tratavam-se da localização dos elementos (período e família) ou curiosidades. Por exemplo, quando se tratava do nitrogênio: "Meu gás é não reativo; Do grupo quinze faço parte; Fixar-me nas plantinhas é para mim uma arte”. Ou quando se falava do Flúor: "Quando escovas o teu dente é de mim que lembras; Na tabela depois do meu grupo só existe o dos nobres“.

Algumas pistas (Tabela 1) tinham por objetivo aproximar o aluno dos elementos químicos, mostrando que vários elementos presente na tabela periódica fazem parte do nosso cotidiano, na composição de materiais de limpeza ou utensílios domésticos, por exemplo, dessa forma é importante conhecê-los e identificá-los.

Tabela 1. Perguntas do jogo.

Adivinhas do Jogo "Advinha quem é sobre a tabela periódica"

Sou o primeiro dos primeiros; E pequeno ao mundo vim; Há uma bomba muito grande; Que é uma bomba em mim.(HIDROGÊNIO)

Sou um sólido bonito; Tenho cor de omelete;Quando ando com iguais; Junto-me sempre a mais sete. (ENXOFRE).

Vou até o teu pulmão; E sou vital para ti; Se estivesses onde não estou; Já não estarias aqui (OXIGÊNIO).

Estou nas cinzas do tabaco; E nas pilhas participo; O Sódio e o Potássio são maiores; Mas são do meu tipo. (LÍTIO).

Estou presente na lixivia; Para a roupa branquear; Encontras-me nas piscinas; Para a água desinfetar. (CLORO).

Meu símbolo tem "N" grande; A ligar-me tenho ódio; Minha Letra segunda é pequena; Mas meu nome não é o Sódio. (NEÔNIO).

Estou no bórax incluído; No pirex também estou; Sou um Berílio sem "e"; Adivinha quem eu sou. (BORO).

$\mathrm{Na}$ água em abundância; Posso matar sem pistola; Sou um metal muito pesado; Da 
lata da Coca-Cola. (ALUMíNIO).

Meus sólidos são muito rígidos; No raio $X$ sou transparente; Tenho um $B$ no meu símbolo; $\mathrm{E}$ a segunda letra diferente. (BERÍLIO).

Minha primeira letra é $\mathrm{M}$; $\mathrm{E}$ a segunda uma vogal; O meu período é o terceiro; Estou no verde vegetal. (MAGNÉSIO).

Sino, Sítio e Silva; São palavras da minha laia; Existo dentro do vidro; E na areia da praia. (SILÍCIO).

Meu símbolo não é F; Embora o faça lembrar; $\mathrm{O}$ isqueiro é meu concorrente; Para ajudar a fumar. (FÓSFORO).

Saber quem sou eu; É fácil de adivinhar; Pois meu próprio símbolo; Está sempre a respirar. (ARGÔNIO).

Existo e dirigíveis; E os ajudo a voar; Pois sou um gás pouco denso; Menos denso que o ar. (HÉLIO).

Meu gás é não reativo; Do grupo quinze faço parte; Fixar-me nas plantinhas; É para mim uma arte. (NITROGÊNIO).

Quando escovas o teu dente; É de mim que lembras; Na tabela depois do meu grupo; Só existe o dos nobres. (FLUOR).

Usam-me em sabões; Eu sou do grupo primeiro; Moro abaixo do Sódio; Acho que sou o terceiro. (POTÁSSIO).

Estou na pedra da calçada; A concha, fui eu que fiz; No quadro preto eu escrevo; Pois eu sou parte do giz . (CÁLCIO).

Com o auxílio das pistas contidas na Tabela 1 e o conhecimento prévio dos alunos a respeito dos elementos químicos, a maioria das questões os alunos acertavam rapidamente, principalmente quando a pista tratava-se da localização do elemento na tabela periódica. Poucas foram as questões que demoravam um tempo maior para achar as respostas, isso só acontecia quando se tratavam de curiosidades sobre o elemento selecionado ou o enigma era muito complexo. Por exemplo, o elemento neônio, a pista não ficou muito clara para os alunos, nesse sentido os alunos tiveram que analisar os demais elementos até acertar esse elemento. O jogo também auxiliou os alunos a compreensão da estrutura da tabela, conseguindo localizar os elementos de acordo com suas características e propriedades. 
Fixado no quadro havia um banner da tabela periódica, em que os alunos poderiam consultar para achar as respostas. O banner disponibilizado aos alunos também exerceu grande importância, já que a maioria dos alunos não apresentava um conhecimento aprofundado sobre a mesma.

Quando a pista disponibilizada fazia referência a alguma curiosidade do elemento em questão, notou-se que os alunos demandavam um tempo maior para encontrar a resposta, mostrando a importância de associar o conteúdo ao cotidiano do aluno abordando no qual podemos encontrar tais elementos no dia-a-dia. A contextualização dos conteúdos através recursos didáticos, desperta o interesse do aluno facilitando a associação e desenvolvimento dos conteúdos abordados, estabelecendo a interação entre a prática e a teoria tornando o processo ensino-aprendizagem mais eficaz (SILVA; BIANCO, 2020).

O espírito competitivo tomou conta da sala durante a aplicação da atividade, todos os alunos queriam vencer o jogo, desta forma estavam comprometidos e engajados em participar e acertar todas as questões. Por meio do jogo, os alunos aprendem além de se divertir. Crespo (2016) afirma que o jogo é uma atividade que estimula a inteligência e o comportamento, já que impõe regras e os jogadores precisam apresentar controle dos seus impulsos.

A cada rodada, os alunos mostravam-se mais motivados, para cada escolha de envelope era pensada uma estratégia. Durante a aplicação do jogo, notou-se a necessidade da confecção de mais pistas quando se tratava de elementos desconhecidos por eles, como por exemplo, o neônio, berílio e o argônio.

Devido o envolvimento dos alunos durante o jogo, assim que as pistas acabaram os alunos solicitaram que novas perguntas e dicas fossem confeccionadas, para que o jogo fosse estendido. Dessa forma, novas pistas foram criadas sobre os elementos, porém devido o curto tempo de confecção, todas as novas pistas tratavam-se da localização dos elementos na tabela periódica, levando o aluno a entender melhor a disposição dos elementos na 
tabela. A forma que conteúdo foi abordado despertou grande interesse, notouse que os alunos não apresentaram tanta dificuldade em acertar os elementos.

O resultado da atividade foi positivo e o objetivo alcançado, já que os alunos conseguiram identificar corretamente os elementos dispostos no painel, com o auxílio das dicas, do conhecimento prévio, conceitos abordados durante as aulas e com o auxílio da tabela periódica que foi disponibilizada durante o jogo, para eventual consulta. Dessa forma, a identificação do conhecimento prévio dos alunos é de grande importância nos processos de aprendizagem, pois facilita a explicação das regras e o andamento do jogo (ZANON; OLIVEIRA, 2008). Para o desenvolvimento de uma aprendizagem potencialmente significativa, a estrutura do conhecimento deve ser organizada, formando uma hierarquia conceitual proporcionando um envolvimento emocional a fim de integrar o conhecimento prévio com o que será adquirido. $O$ aluno aprenderá a partir do que ele já tem conhecimento, dessa forma o conhecimento prévio dos alunos organizados de forma hierárquica, influenciará a aprendizagem significativa dos novos conhecimentos adquiridos (AUSUBEL, 2003).

\section{Considerações finais}

Com base na atividade desenvolvida e aplicada, o jogo "Adivinha quem é na tabela periódica" pode ser uma alternativa para mediação dos conteúdos sobre tabela periódica e elementos químicos no $9^{\circ}$ ano do EF. A utilização do jogo como recurso didático proporciona um ambiente criativo e de interação entre os alunos e professor. Além disso, o jogo permite que o professor amplie seus conhecimentos, habilidades e adote metodologias diferenciadas de ensino, permitindo-o uma reflexão sobre sua prática docente e pensando no aluno com centro de seu processo de ensino e aprendizagem.

A utilização de jogos didáticos no ensino de química exerce grande influência entre os alunos, e pode atuar como um facilitador de ensino, já que promove a interação entre os alunos. O uso de materiais didáticos diferenciados no ensino de química pode despertar o interesse do aluno pelo 
conteúdo, promovendo um ensino mais prazeroso e dinâmico e não apenas de memorização dos conceitos propostos na disciplina.

O ensino de química apresenta linguagens técnicas, conteúdos complexos e abstratos, que na maioria das vezes é de difícil compreensão para os alunos. Nesse sentido, o jogo torna-se um importante instrumento que motiva e estimula a aprendizagem dos alunos, promovendo a compreensão de conceitos químicos, desenvolvimento de habilidades, estimula a criatividade e participação dos alunos.

Além da revisão e fixação do conteúdo de tabela periódica e elementos químicos, foi possível identificar a motivação dos alunos durante as aulas após a aplicação do jogo. Os alunos apresentaram mais empenho quando o assunto abordado era a tabela periódica, reforçando que a utilização de estratégias de ensino diferenciadas exerce um importante papelno processo de aprendizagem dos alunos.

\section{Referências}

ANDRÉ, Marli. O que é um estudo de caso qualitativo em educação? Revista da FAEEBA - Educação e Contemporaneidade, Salvador, v. 22, n. 40, p. 95103, jul./dez. 2013.

BATLLORI, Jorge. Jogos para treinar o cérebro: desenvolvimento de habilidades cognitivas e sociais. Tradução Fina Iñiguez. São Paulo: Madras, 2003.

BRAULIO, Ana Marilsa; ALMEIDA, Fernanda Losi Alves. Introdução do ensino de química no $9^{\circ}$ ano por meio de atividades experimentais. Paraná, 2013.

CASTRO, B. J. ; FRASSON-COSTA, P.C . Contribuições de um jogo didático para o processo de ensino e aprendizagem de Química no Ensino Fundamental segundo o contexto da Aprendizagem Significativa. REVISTA ELECTRÓNICA DE INVESTIGACIÓN EN EDUCACIÓN EN CIENCIAS (EN LÍNEA) , v. 6, p. 25-37, 2011.

COSTA, Nelson Lage da.A Formação do Professor de Ciências para o Ensino da Química do $9^{\circ}$ ano do Ensino Fundamental - A Inserção de uma Metodologia Didática Apropriada nos Cursos de Licenciatura em Ciências Biológicas. 2010. 75.

CRESPO, Larissa Codeço; GIACOMINI, Rosana; As atividades lúdicas no ensino de química: uma revisão da revista química nova na escola e das 
reuniões anuais da sociedade brasileira de química; Universidade Estadual do Norte Fluminense Darcy Ribeiro/ Centro de Ciência e Tecnologia Laboratório de Ciências Químicas;

FREIRE, Paulo. Pedagogia da autonomia: saberes necessários á prática educativa. São Paulo: Paz e Terra, 1996.

Gomes, H.J.P.; Oliveira, O.B. (2007). Obstáculos epistemológicos no ensino de ciências: um estudo sobre suas influências nas concepções de átomo. Ciências \& Cognição, Rio de Janeiro, v. 12, n. 1, p.79-109. Quadrimestral. Disponível em:<http://cienciasecognição.org/pdf/v12/m347194.pdf > Acesso em: 12 Abril 2021

KRASILCHIK, Myriam. Prática de Ensino de Biologia. São Paulo: Edusp, 2008.

MAZZEI, Roberto. Adivinhas sobre a tabela periódica. Disponível em: https://professormazzei.com/mazzei-com/jogos-de-quimical. Acesso em 01/12/2019.

MOREIRA, Marco. Antônio. O que afinalé a aprendizagem significativa.PORTO ALEGRE, 2012.

MORSCHHEISER, Luana Marciele. SAL, Francieli. OLIVEIRA, Thais Cristina Dick Cardozo de. PADILHA, Simara Perin. BALDISSERA, Rosane Aparecida. A Potencialidade Da Tabela Periódica Como Objeto Educacional Inclusivo No Espaço-Tempo Do Pibid De Química - UFFS REALEZA - PR, 2017.

PIRES, Janyne Soares Braga; FURIERI, Karina Schmidt; COELHO, Fernanda Tesch; MAGEVSKI, Laís da Silva; MACIEL, Hadassa Pedra; DUARTE-SILVA, Érica. Os desafios docentes no ensino de ciências: Desenvolvimento de um material paradidático contextualizado para o ensino de botânica na Ilha de Guriri-ES, Bioma Mata Atlântica. In: Conservação da Biodiversidade e desenvolvimento socioambiental. Editora Atena. Ponta Grossa-PR, 2020. Disponível em: https://www.researchgate.net/publication/341901486 os desafios docentes n o ensino de ciencias desenvolvimento de um material paradidatico contex tualizado para o ensino de botanica na ilha de guriries bioma mata atlantica.

RAU, M. C. T. D. A ludicidade na educação: uma atitude pedagógica. Curitiba: Ibpex, 2007.

ROCHA, DIEGO. FLORIANO.; Rodrigues, MARCELLO DA.SILA. .Jogo didático como facilitador para o ensino de BIOLOGIA no ensino médio. CIPPUS - REVISTA DE INICIAÇÃO CIENTÍFICA DA UNILASALLE, v. v.8, p. 01-08, 2018.

ROQUE, N. F.; SILVA, J. L. P. B.A Linguagem Química e o Ensino da Química Orgânica. In: Química Nova, v. 31, n. 4, p. 921-923, 2008. 
ROSA, Liane da Serra. Desafios de formação do professor de ciências para o ensino fundamental. Rio Grande, 2015.

SANTOS, Adriana Vieira Dos. ARAÚJO, Felipe Barbosa.Utilização De Jogo Didático Para $O$ Ensino De Tabela Periódica.Revista eletrônica LudusScientiae -(RELuS) | V. 1, N. 2, Ago./Dez. 2017.

SILVA, Joselia Cristina Siqueira Da ; BIANCO, Gilmene. Jogos didáticos: a

formação educativa através de uma aprendizagem significativa e um currículo adaptado por projetos. Research, Society And Development, v. 9, p. e820997969, 2020.

Untar, S. (2008). A química no ensino fundamental e os conhecimentos dos professores das escolas municipais da cidade de Várzea Grande - MT. 145 f. Dissertação de Mestrado.Universidade Federal de Mato Grosso, Universidade Federal de Mato Grosso, Cuiabá, Brasil. Disponívelem:<http://www.dominiopublico.gov.br/pesquisa/DetalheObraForm.d o?select_action=\&co_obra=122728>Acessoem :12 abril. 2021.

UNTAR, S. A química no ensino fundamental e os conhecimentos dos professores das escolas municipais da cidade de Várzea Grande-MT. 145 f. 2008. Dissertação (Mestrado em Educação na Área de Concentração: Teorias e Práticas Pedagógicas da Educação Escolar) - Universidade Federal de Mato Grosso - UFMT. Cuiabá (MT), 2008.

ZANON, Dulcimeire Aparecida Volante ; MANOEL; OLIVEIRA, Robson C. Jogo didático Ludo Químico para o ensino de nomenclatura dos compostos orgânicos: projeto, produção, aplicação e avaliação. CIÊNCIAS \& COGNIÇÃO (UFRJ) , v. 13, p. 72-81, 2008.

\section{Sobre os autores}

\section{Janyne Soares Braga Pires}

janynesbraga@hotmail.com

Graduada em Licenciatura em Ciências Biológicas no ano de 2017 pela Universidade Federal do Espírito Santo (UFES) e em Pedagogia no ano de 2019 pela Cruzeiro do Sul. Pós-graduada em Educação Especial Inclusiva pela Faculdade Alfa América no ano de 2018. Pós-graduanda em Análises Clínicas e Microbiologia pela Faculdade de Venda Nova do Imigrante (FAVENI). Mestre em Ensino na Educação Básica pela Universidade Federal do Espírito Santo (UFES) no ano de 2021.

\section{Gilmene Bianco}

gilmeneb@yahoo.com.br

Graduada em Química pela Universidade Federal de Santa Catarina, mestre em química pela Universidade Federal de Santa Catarina e doutorado 
em Química pela Universidade de São Paulo (2001). Atualmente professora associada da Universidade Federal do Espírito Santo. 